\title{
Impfpflicht in Europa
}

\section{Derzeit in aller Munde - aber gibt es wissenschaftliche Evidenz?}

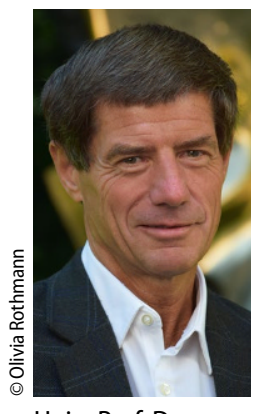

Univ.-Prof. Dr. Reinhold Kerbl

\author{
1) \\ Mandatory Vaccination in Europe. \\ Vaz OM, Ellingson MK, Weiss P, Jenness SM, Bardají A, Bednarczyk RA, Omer SB. \\ Pediatrics. 2020 Feb;145(2). pii: e20190620. https://doi.org/10.1542/peds.2019-0620. \\ Epub 2020 Jan 13. \\ PMID: 31932361 \\ 2) \\ Vaccination Policies and Disease Incidence Across the Pond: Implications for the \\ United States. \\ O'Leary ST, Maldonado YA. \\ Pediatrics. 2020 Feb;145(2). pii: e20192436. https://doi.org/10.1542/peds.2019-2436. \\ Epub 2020 Jan 13. \\ PMID: 31932360
}

\section{Hintergrund}

Mit März 2020 hat sich Deutschland unter jene Länder eingereiht, die eine (begrenzte) Impfpflicht verfügt haben. Absicht dieser Maßnahme ist es, die Impfraten zu erhöhen, den Gemeinschaftsschutz zu stärken und damit weitere "Outbreaks" v.a. von Masern möglichst zu verhindern. Bisher gibt es allerdings nur wenig Daten über die Effektivität einer Impfpflicht. Eine jüngst in Pediatrics publizierte Analyse

hat eben diese Fragestellung näher untersucht.

\section{Methode}

Die retrospektive Analyse erfolgte für 29 europäische Länder und erfasste die Impfprävalenz und Erkrankungsraten für Masern (Zeitraum 2006-2015) und Pertussis (2006-2006). Dafür wurden Daten des European Centre for Disease Prevention and Control (ECDC) und der World Health Organisation (WHO) he-

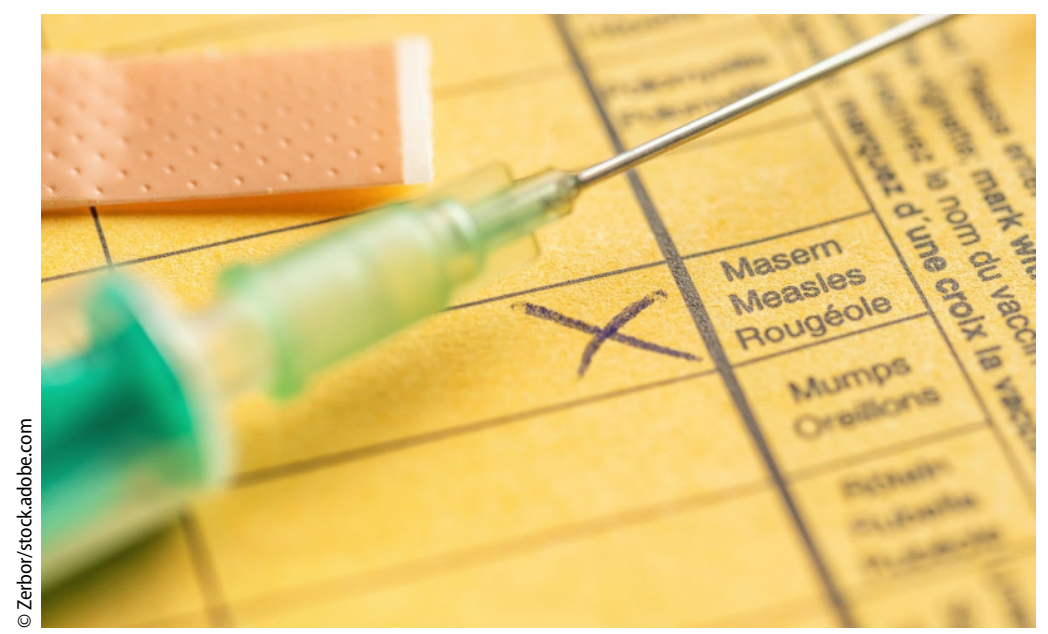

A Impfpflicht kann die Beteiligungsraten sowohl für die Masern- als auch die Pertussisimpfung signifikant erhöhen, so die Ergebnisse einer Studie rangezogen. Weiters wurde erhoben, ob bzw. welche Sanktionen in jenen Ländern bestehen, die eine Impfpflicht haben.

\section{Ergebnisse}

Von 29 europäischen Ländern hatten im Beobachtungszeitraum sieben Länder eine begrenzte Impfpflicht. Es waren dies (in alphabetischer Reihenfolge) Bulgarien, Litauen, Slovakei, Slovenien, Tschechien, UK und Ungarn. Außer in Litauen hatte in allen Ländern die Impfverweigerung eine Geldstrafe in Höhe von 50 bis 1600 Euro zur Folge, die höchsten Strafen wurden für Ungarn erhoben. Zwei Länder (Litauen und Bulgarien) ließen neben medizinischen auch nicht-medizinische Ausnahmegründe zu.

Bestehende Impfpflicht führte im Mittel zu einer Steigerung der Impfprävalenz um 3,71\% (Masern) bzw. 2,14\% (Pertussis). Bezogen auf die Erkrankungsrate an Masern zeigte sich nur für jene Länder ein Vorteil, die keine nicht-medizinischen Ausnahmen zuließen. Für Pertussis ergab sich durch Impfpflicht keine signifikante Reduktion der Erkrankungsrate.

Beim Vergleich der angedrohten bzw. verhängten Geldstrafen zeigte sich, dass pro 500 Euro die Impfrate für Masern um $0.8 \%$ gesteigert werden konnte, jene für Pertussis um 1,1 \%.

\section{Kommentar}

Seit Beendigung der Datenerhebung für die oben zitierte Studie [1] wurde eine begrenzte Impfpflicht im Jahr 2017 auch in Italien und Frankreich eingeführt, mit März 2020 folgte nun auch Deutschland. Derartige Neueinführungen der Impfpflicht sind meist von emotionalen bis militanten Reak- 
tionen von Impfskeptikern und Impfgegnern begleitet, und finanziell besser gestellte Familien nehmen oft auch Geldstrafen in Kauf.

Die Ergebnisse dieser Studie zeigen, dass Impfpflicht die Beteiligungsraten sowohl für die Masern- als auch die Pertussisimpfung signifikant erhöhen kann. Damit besteht auch die Chance, die Impfprävalenz so weit anzuheben, dass ein Gemeinschaftsschutz (früher als „Herdenschutz" bezeichnet) erreicht werden kann. Eine signifikante Reduktion der Erkrankungsrate für Masern ist allerdings scheinbar nur dann zu erzielen, wenn keine nichtmedizinischen Ausnahmen zugelassen werden. Dass die Erkrankungsrate für Pertussis bei Impfpflicht nicht signifikant niedriger lag, begründet ein in derselben Ausgabe von Pediatrics publizierter Kommentar [2] damit, dass Pertussis-„Outbreaks“ multifaktoriell bedingst sind, sodass Impfver- weigerung dabei relativ weniger Rolle spielt als bei Masern. Die Autoren der Studie [1] und jene des Kommentars [2] stimmen überein, dass Impfpflicht EINE Maßnahme zur Erhöhung der Impfprävalenz sein kann, dass aber auch alle anderen Möglichkeiten ausgeschöpft werden müssen.

Interessanterweise wird nun vielfach schon über eine Impfpflicht gegen COVID-19 spekuliert. Dabei wissen wir noch nicht einmal, ob uns dieses Virus länger begleiten wird und ob bzw. wann es einen wirksamen Impfstoff geben wird....

\section{Korrespondenzadresse}

\section{Reinhold Kerbl}

Abteilung für Kinder- und Jugendheilkunde, LKH Hochsteiermark, Standort Leoben Vordernberger Straße 42, 8700 Leoben, Österreich

reinhold.kerbl@kages.at

\section{Literatur}

1. Mandatory Vaccination in Europe. Vaz OM, Ellingson MK, Weiss P, Jenness SM, Bardají A, Bednarczyk RA, Omer SB (2020) Pediatrics. https://doi.org/10.1542/peds.2019-0620

2. O'Leary ST, Maldonado YA (2020) Vaccination Policies and Disease Incidence Across the Pond: Implications for the United States. Pediatrics. https://doi.org/10.1542/ peds.2019-2436

Hinweis des Verlags. Der Verlag bleibt in Hinblick auf geografische Zuordnungen und Gebietsbezeichnungen in veröffentlichten Karten und Institutsadressen neutral.

Paediatr. Paedolog. 2020 · 55:152-153 https://doi.org/10.1007/s00608020-00793-2

(c) Springer-Verlag GmbH Austria, ein Teil von Springer Nature 2020

Hier steht eine Anzeige. 